\title{
Gasgeochemical indicators seismic activity
}

\author{
Anatoly Obzhirov \\ V.I.Il'ichev Pacific Oceanological Institute (POI) FEB RAS, Russia, 690041, Vladivostok. \\ Baltiyskaya str. 43
}

\begin{abstract}
Laboratory of Gasgeochemistry of POI FEB RAS is studying gas distribution in lithosphere, hydrosphere and atmosphere from 1977 years. Method consist is sampling from its in expedition, take gas from samples of sediment, water and atmosphere to use method degassing and analysis gas in chromatograph, to measure $\mathrm{CH} 4, \mathrm{C} 2-\mathrm{C} 4, \mathrm{O} 2, \mathrm{~N} 2, \mathrm{H} 2, \mathrm{He}$ and some time Rn. Gas is using like indicators to search oil-gas deposits, gas hydrate, mapping zones faults, to determine seismic activity, to calculate green house gas $(\mathrm{CH} 4, \mathrm{CO} 2)$. The next geological, geophysics and hydro-acoustics characteristics assist which help to explain to form methane bubbles fluxes and gas hydrate in the Okhotsk Sea. The methane fluxes are mostly located in the zones faults and it increase in period seismic activity.
\end{abstract}

\section{Introduction}

The first discovery of methane fluxes and gas hydrate field in the Okhotsk Sea was in the 1988 year. After it many international expedition were provided in Sakhalin shelf and slope of the Okhotsk Sea (fig.1) to search flux of methane and gas hydrate. It carried out in frame international projects - KOMEX (Russian-Germany, 1998-2004), HAOS (Russian-JapanKorea, 2003, 2005-2006), SAKHALIN (Russian-Japan-Korea, 2007-2015), GASHYDRATE (Russian-China, 2016-2018). During the process of gas geochemistry investigations in period 1988-2016 in the Okhotsk Sea were found 500 gas fluxes, 17 areas with gas hydrate. Gas bubbles migrate via zones faults from sediment to water and some part to atmosphere. The next component of gas explain fellow. Methane and heavy hydrocarbon (C2-C4) show content oil-gas deposit and gas hydrate in the structure, $\mathrm{CO} 2$ is indicator to presence intrusion complex and $\mathrm{H} 2$, He show appear deeper flux of gas from bottom lithosphere or mantel via zone fault because of seismic activity. Concentrations and quantity gas components relationship with seismic-tectonic activity or period stability of it. In Far-Eastern regoin this process to start from 1988. and it to continue now. In zones faults with fluxes gas sediment in bottom Sea to disturb, to appear pits and knoll (valleys and mountains) $10-20 \mathrm{~m}$ size and to appear layers of gas hydrates, carbonate concretions, benthos and other modification. It is very important that quantity and power of methane fluxes increase in period seismic activity of the Far Eastern Seas region. It may use like indicator seismic activity and earthquake prognosis. Methane is going from deep layers to

Corresponding author: obzhirov@poi.dvo.ru 
up in surface sediment and water column via zone fault. Sources of methane are oil-gas bearing layers and more deeper horisonts of litosphere

\section{Method of investigations}

It is very important to use geological complex to study methane flaxes and gas hydrate. 12 international Russian-Japan-Korea expeditions from 2003 to 2015 years were conducted on the East Sakhalin slop of the Okhotsk Sea using the Russian research vessel "Akademik M.A.Lavrentyev". All geological, geophysical, gas geochemical, hydro-acoustic, morphostructure complex are very important indicator to search methane fluxes and gas hydrate and to understand regularity to form and to destroy of its. Multidisciplinary data were obtained during these expeditions: hydro-acoustic profiling using single-beam echosounders, seafloor imaging using side-scan sonar (SSS), seismic reflection profiling using a sub-bottom profiler and sparker-source seismic system, CTD profiling, water column sampling from bottom to surface using a Rosette sampler and near-bottom sediment and gas hydrate sampling using a gravity and hydro corer

Gas bubbles in the water column have high impedance contrast relative to water and appear on echograms as hydro-acoustic sound-scattering anomalies like vertical flux (gas "flares") in water column from Sea floor to up in surface (figures 1a and 1b). The hydroacoustic systems 'ELAC' and/or 'Sargan-EM' were used simultaneously with frequencies of 12, 20, and $135 \mathrm{kHz}$ to detect gas flares [2, 10, 14].
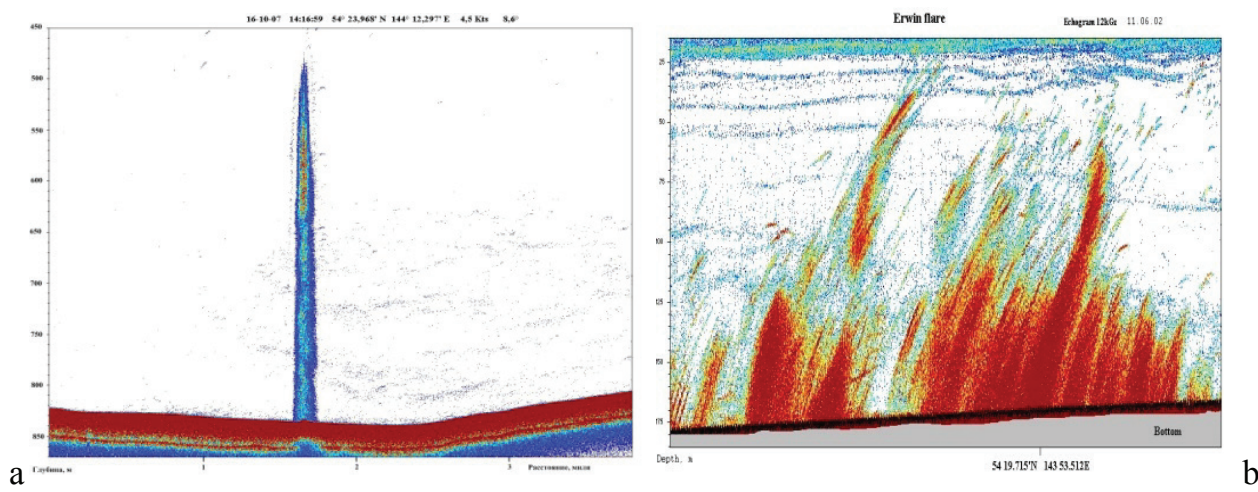

Fig. 1. a) Hydro-acoustics image of methane babbles flux from sediment to water in the Sakhalin slope of Okhotsk Sea (depth $820 \mathrm{~m}$ ), b) Gas flux in the shelf, depth $175 \mathrm{~m}$

Deep-tow side-scan sonar surveys were conducted using the 'SONIC-3' system with a frequency of $30 \mathrm{kHz}$ in a medium-range mode and a swath range of 800-3200 m. Width range is $500-2,000 \mathrm{~m}$, and the best resolution is $2.0 \mathrm{~m}$. The 'SONIC-3M' system is also equipped with a sub-bottom profiler with a frequency of $8 \mathrm{kHz}$ (maximum resolution $=0.3$ $\mathrm{m})$. The sonar "fish" was towed at 90-120 m above the seafloor and ship speed was 2-4 knots [2].

High-frequency seismic data were obtained using the sparker system made in Russia [14]. The system used a sparker with a frequency range of $200-1,200 \mathrm{~Hz}$ and an energy of $500-2000 \mathrm{~J}$ as a source, and a single-channel streamer as a receiver. The system provides a resolution of 2-5 $\mathrm{m}$ for sediment layer thickness and a bottom penetration of 50-300 m. To measure concentrations 'methane, heavy hydrocarbon (C2-C4), CO2, H2, O2, N2 in the water column and sediment was used method Head Space and degassing. Water for gas analyze was taken from Niskin bottles in glasses volume $128 \mathrm{ml}$ with added chlorhexidine 
$(0.05 \%)$ to preserve natural gas from microbial change some concentration of it and immediately close with contact of air. Pure helium was used as the gas phase and it was added into glasses with water sample. Gas sample is injected into the chromatograph after intensive manual shaking and stirring on the mixer LS110 during four and more hours. Gas chromatograph "Cristall - Lux 4000M" (Russia) equipped with a flame ionization detector and two thermal conductivity detectors (FID/2 and TCD) used for gas chromatographic analysis the gas composition on board (figure 2a). Methane concentration was calculated as the sum of the dissolved fraction [14] and methane gas phase. The precision of the analysis was $5 \%$.

The sediment samples to measure gas were taken from core with $12 \mathrm{ml}$ plastic syringes via $20 \mathrm{~cm}$ interval (figure 2b). It transferred into $68 \mathrm{ml}$ glasses with a saturated water solution of $\mathrm{NaCl}$ containing $0.5 \mathrm{ml}$ of chlorhexidine $(0.05 \%)$. Then following the procedures described to measure gas in water samples o use method of Head space. Calculation of methane in sediments produced without the dissolved fractions of gas in water solution of $\mathrm{NaCl}$.
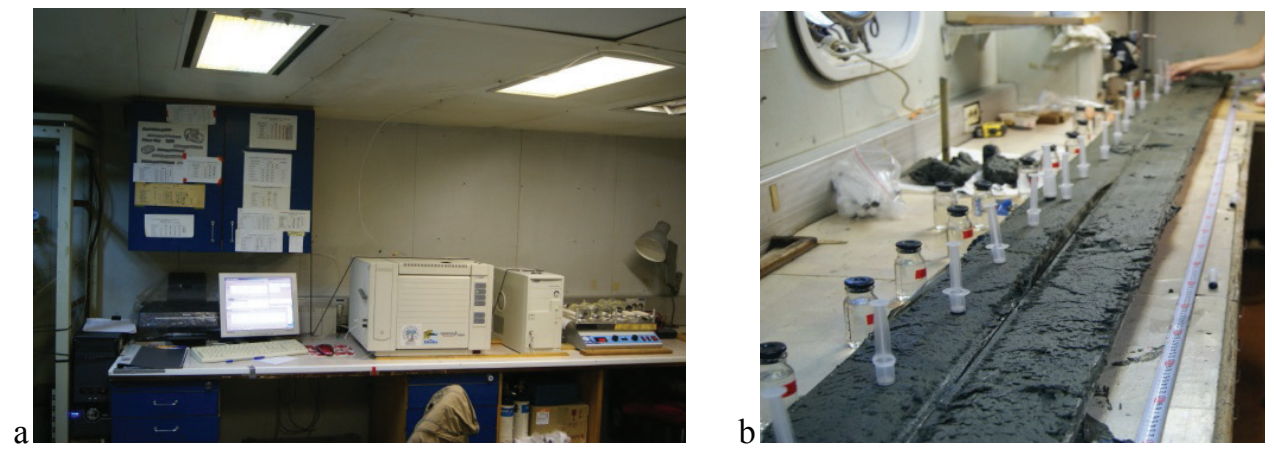

Fig. 2. a) Gas chromatograph "Cristall - Lux 4000M" (Russia), b) Sampling sediment from core to measure gas.

\section{Results of investigation and discussion}

Sea of Okhotsk located between different lithosphere plates - Amur, Eurasian, NorthAmerican, Bering and Pacific (figure 3a). Relationship between lithosphere plates, regional blocks and active of asthenosphere in this area to support to form rifts, magma, faults and fluxes of gas-fluid (figure 3b). In the Okhotsk Sea took place riftogenesis that had 5 periods activity - early Paleocene, middle-later Eocene, later Oligocene, middle-later Miocene and Pliocene-Quaternary [4]. In these periods gorst- and graben- structures were formed. They creates good condition to form sediment basins. This process leaded to appear fold, flexure, zone fault in sediment basins especially in period global compression. To form of the folds and other structures in sediment basins was in different periods volcano and seismic activity. Thickness sediment in basin create about 7-8 km that was great condition to form oil-gas deposit in the Okhotsk Sea. It is very important that in East Sakhalin shelf and slop area of the Okhotsk Sea present zone destruction of the earth's crust and slide faults. These structures are zones for gas-fluid fluxes from, possible, asthenosphere and oil-gas-bearing layers to surface sediment. 

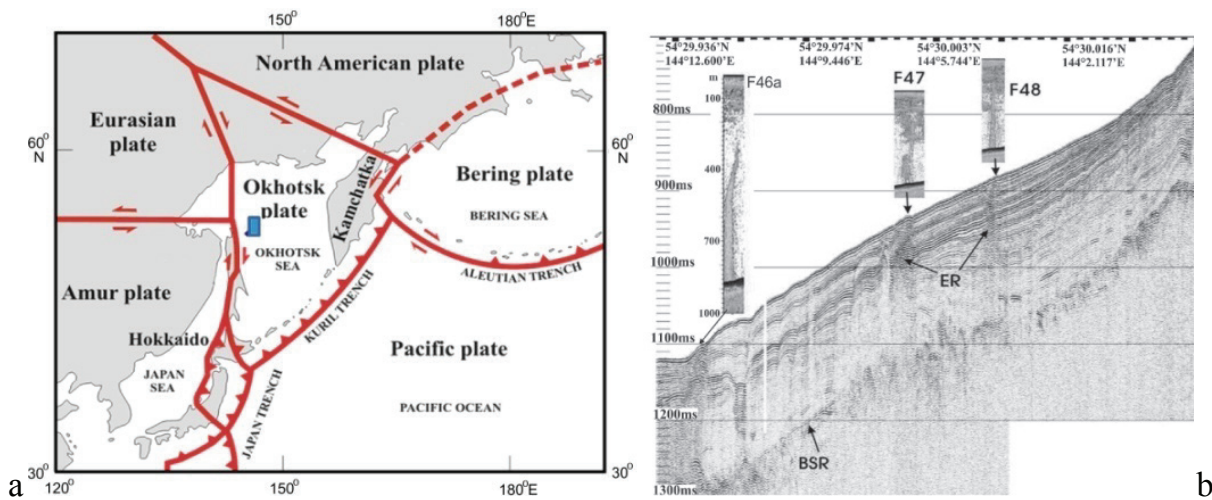

Fig. 3. a) Scheme to locate Okhotsk plate between fellow plates: Amur, Europe-Asian, NorthAmerican, Bering, Pacific. Lines between plates are seismic active contact between its and zones different faults. b) Profile with methane fluxes from sediment to water (F46a, F47, F48). BSR (bottom simulating reflector), gas hydrate is locate in sediment between surface and BSR, ER different chimneys (gas tubes)

Methane distribution in the Okhotsk Sea was studied since 1984 [7, 8, 9]. The first purpose was to search oil and gas deposit to use gas (especially hydrocarbon) as indicator of oil and gas structures. In period this investigation the first methane flux (1988) and gas hydrate (1991) was found [3,8]. After it many international expedition were provided on the Sakhalin shelf and slope of the Okhotsk Sea to search methane fluxes and gas hydrates $[6,10,14]$.

Every year a new methane bubbles fluxes (flares) from sediment to water column were found. Methane concentration in bottom water column reaches 1000-10000 nl/1 and in sediment are $10-100 \mathrm{ml} / \mathrm{l}$ on mostly of areas with methane fluxes.(figures $4 \mathrm{a}$ and $4 \mathrm{~b}$ ).
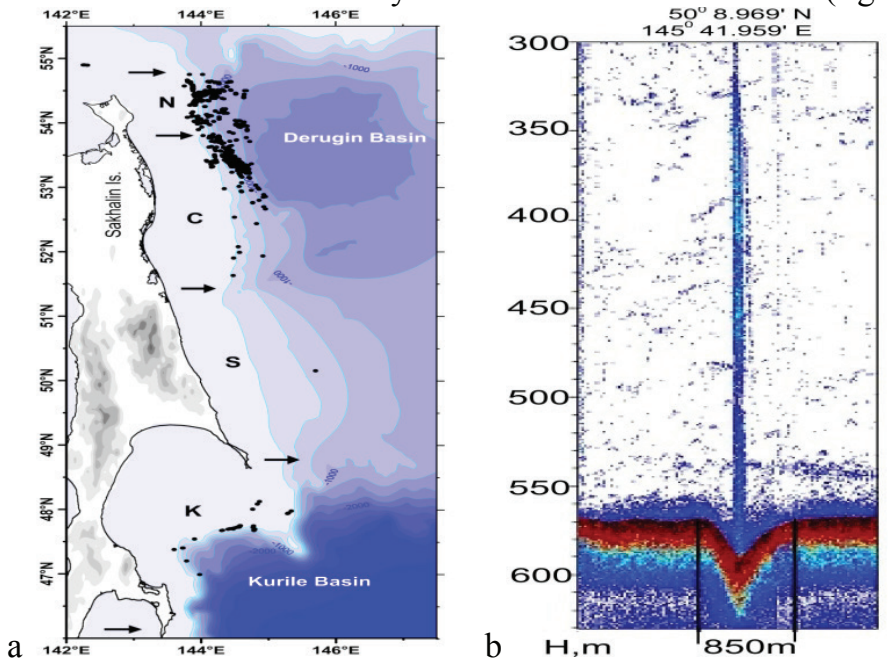

Fig. 4. a) The methane fluxes (black points) on Sakhalin slope of the Okhotsk Sea (N-North part, CCenter part, S-South part, K-Kuril area)

b) Hydroacoustics image of methane babbles flux from sediment to water in the Sakhalin slope of Okhotsk Sea. Methane flux located in the point of area S 
Monitoring investigation show that numbers of methane fluxes were increased during in the period of seismic-tectonic activity in the Okhotsk Sea. It starts from 1988 and continue now (figures 5a and 5b). It regularity supports episodes of earthquakes - 1995Neftegorsk, 2001-Uglegorsk, 2003-Khokkaido, 2007-Nevel'sk, Fukusima (2011) and other $[2,10]$.
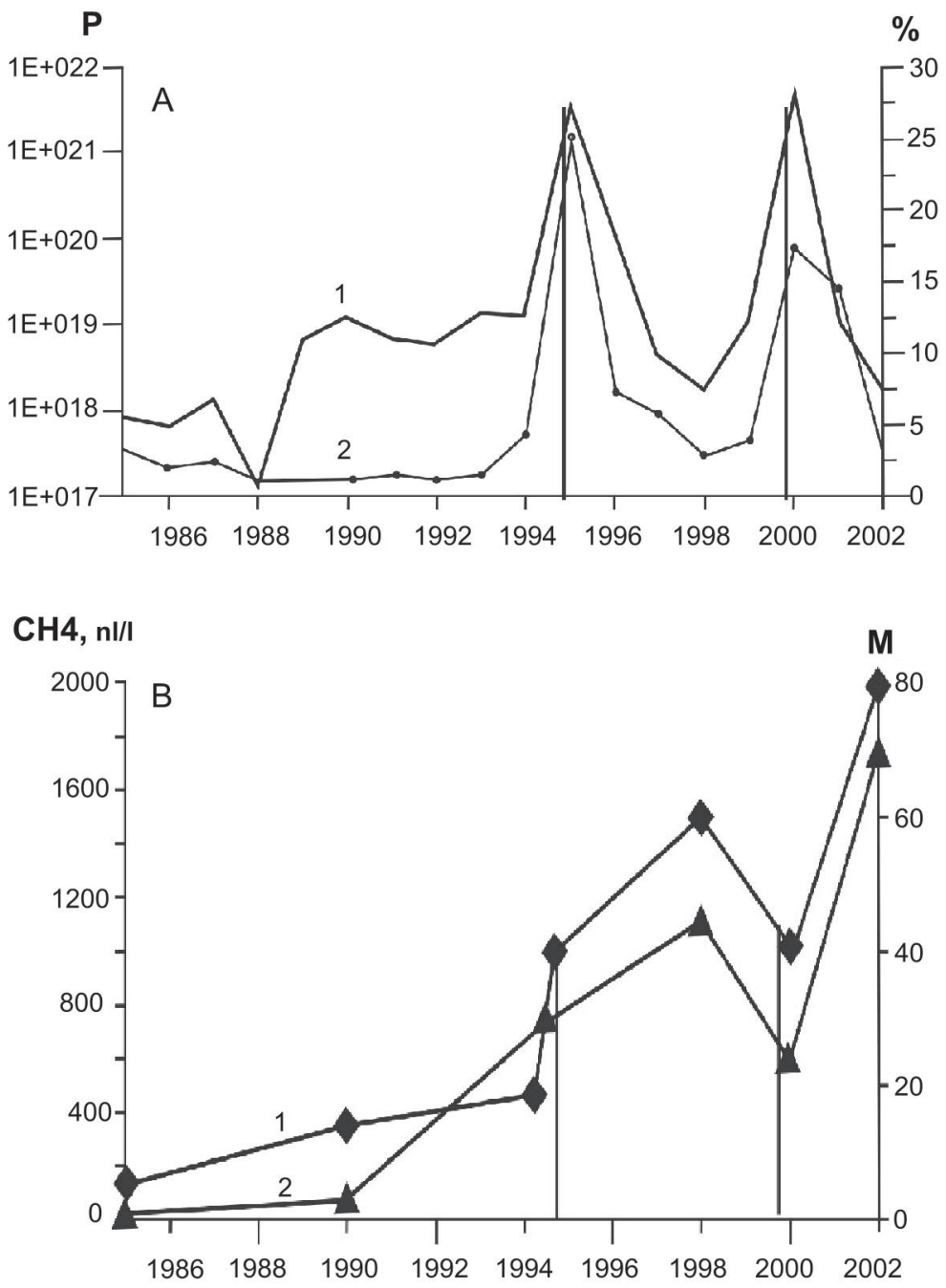

Fig. 5. a) Line 1 show energy ( $P$, in 1 Erg +0.17 and more) of earthquake in different years (from 1986 to 2002). Line 2 is number of earthquakes magnitude $M>3$. b) Line 1 show methane concentration in bottom water in the various years, Line 2 is number of methane fluxes every year.

When methane bubbles come up from oil-gas deeper layers to the seafloor gas hydrate is formed in near surface layers sediment in gas hydrate stability zone. Below this zone of gas hydrate-bearing layers of sediment (BSR), free gas accumulates. If zone fault activities pass way increase and free gas (mostly methane) come up in surface sediment and water. Methane reachs the seafloor and in cool temperature and enough pressure to create gas hydrate in the stable condition of gas hydrate forming. A second (new) gas hydrate layers 
form near seafloor sediment usually with $\mathrm{cm}$-scaled layer or fragments in the water depth deeper $400 \mathrm{~m}$.

In period seismic activity methane bubbles come up to the sea floor from the oil-gasbearing sediment to use zone fault and to form gas hydrate. In period seismic stability methane fluxes absent and gas hydrate could not form. In this period mud sediment accumulates. Its processes are repeated in seismic activity (figure 6a).
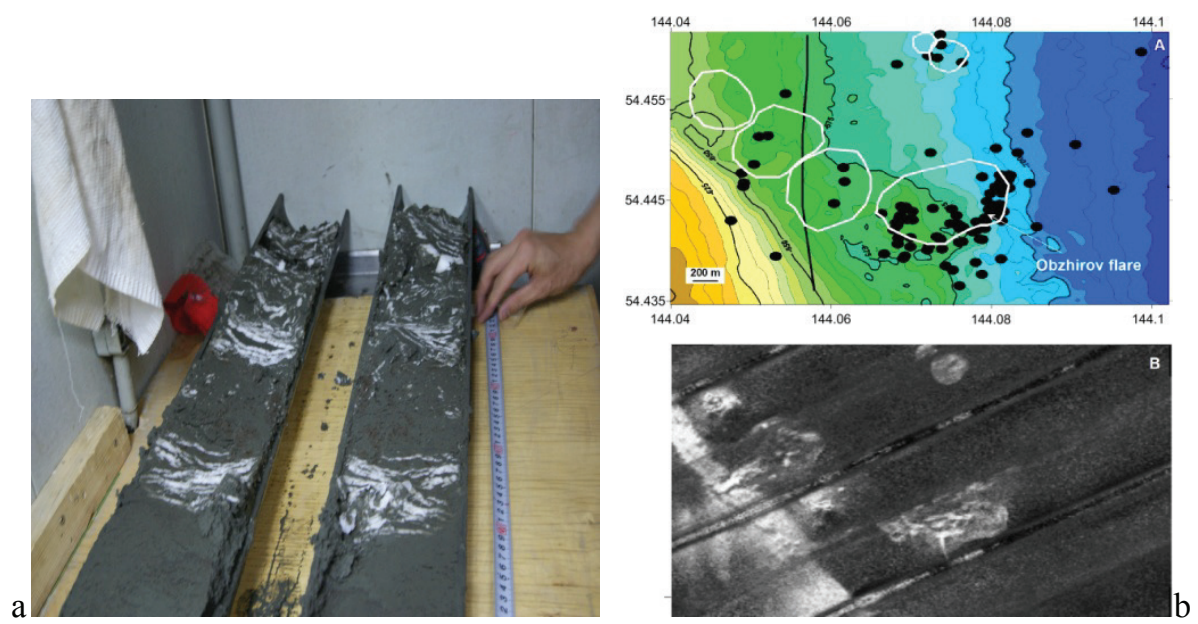

Fig. 6 a) Grey color is layers with silt sediment. White color is layers with gas hydrate. b) (top part) Black points are methane fluxes in the area of the Okhotsk Sea near Obzhirov flare. (low part) White some circular areas are side sonar scanner image on surface sediment where gas (mostly methane) fluxes come up from sediment to water and to destroy sediment surface and forming hillocks and pits.

Sea floor in the area with methane flux is destroyed. Holes and hillocks like mud volcanoes with diameter of 100-800 $\mathrm{m}$ (figure 6b, top and low) are formed in this area. In sea floor of methane flux area a new assemblage, many shell and other benthos, crab and fish usually appeared. In near surface sediment layers carbonate fragment and concretions are formed.

\section{Conclusion}

So, methane fluxes and high methane concentration in the bottom water are considerable indicators to search gas hydrates in marine sediments. The increasing quantities of methane flares and methane concentrations in water column since 1988 are connected with seismic and tectonic activity of the faults in the Okhotsk Sea. In the other side, in the area with methane fluxes the morphology of sea floor is changing (hills and holes appear). The chimney structure is forming in the sediments with raising up gas. In this area sediments shells, carbonate concretions and other mineral association appear.

Geological, geophysical, gas geochemical, hydro-acoustic, morpho-structure surveys are very important indicators to search gas hydrates and to understand regularity forming and destroying of gas hydrates $[10,11,12,14,16]$. Thus, integrated complex of investigations with international cooperation allow us to discover methane fluxes, gas hydrates and to understand formation/dissociation gas hydrates in the Okhotsk Sea. This researches help to find much geological regularities around gas hydrate in the Okhotsk Sea as well as to examine relationships between methane fluxes, gas hydrates and oil and gas deposits. 
Methane of thermogenic origin forms gas hydrates. It is important to understand because that feature influences on searching gas hydrate method, and on examine of methane volume in gas hydrate field and on mining methane from gas hydrates [13]. In general gas hydrate reserves methane and become a good cap to save all hydrocarbons. In geological period with seismic activity methane and other gases go up to the surface through fault zones and form gas hydrate in stability conditions. In period changing geological conditions sediment accumulation occurs and gas hydrate is buried in deeper zone. When conditions become unstable gas hydrates transform to methane. One part of methane forms gas and oil deposits and other part goes up to form a new gas hydrate. This argument helps to work out hydrocarbons from gas hydrates.

\section{References}

1. Akihiro Hachikubo, Alexey Krylovjjj, Hirotoshi Sakagami, Hirotsugu Minami, Yutaka Nunokawa, Hitoshi Shoji, Tatiana Matveeva, Young K. Jin, Anatoly Obzhirov. GeoMarine Letters, 30:3-4 (2010)

2. Baranov B.V., Jin Y.K., Shoji H., Obzhirov A., Dozorova K.A., Salomatin A., Gladysh V. (2008) Gas Hydrate System of the Sakhalin Slope: Geophysical approach. (Scientific Report of the Sakhalin Slope Gas Hydrate Project 2007. KOPRI)

3. Ginsburg G.D., Soloviev V.A., Cranston R.E., Lorenson T.D., Kvenvolden K.A. GeoMarine Letters, 13 (1993)

4. Kharakhinov V.V. Oil and gas geology of the Sakhalin region (Scientific World, Moscow, 2010) (in Russian)

5. Lein A.Yu., Ivanov M.V. Biogeochemical cycle of methane in ocean (Nauka, Moscow, 2009) (in Russian)

6. Hirotsugu Minami, Kazuya Tatsumi, Akihiro Hachikubo, Satoshi Yamashita, Hirotoshi Sakagami, Nobuo Takahashi, Hitoshi Shoji, Young Keun Jin, Anatoly Obzhirov, Nataliya Nikolaeva, Alexander Derkachev. Geo-Marine Letters. 32:5 (2012)

7. Obzhirov A.I., Kazansky B.A., Melnichenko Yu.I. Pacific Geology, 2 (1989) (in Russian).

8. Obzhirov A.I. Gas geochemical fields in bottom water of seas and oceans (Science Publ., Moscow, 1993) (in Russian).

9. Obzhirov A.I. et .al. Methane monitoring in the Sea of Okhotsk (Dalnauka, Vladivostok, 2002) (in Russian).

10. Obzhirov A., Shakirov R., Salyuk A., Suess E., Biebow N., Salomatin A. Geo-Marine Letter, 24:3 (2004).

11. A.Obzhirov, V.Yusupov, A.Salomatin. Gas-Hydroacoustic complex to estimate seismic-tectonic activity. (Patent. RU № 78333 U1, 2008. Bull. No 32)

12. Obzhirov A.I. Method to search hydrocarbon deposit (Patent RU 2359290 C1. 2009. Bull. No 17)

13. Obzhirov A.I. Tagiltsev A.A. Technological complex to mining methane from gas hydrate in the open Sea (Patent. RU 2386015 C1. 2010. Bull. No 10)

14. Operation Report of Sakhalin Slope Gas Hydrate (SAKHALIN) Project 2011, R/V Akademik M.A.Lavrentiev Cruise 56 (2012) New Energy Resources Research Center, Kitami Institute of Technology, Kitami, H. Shoji, Y.K. Jin, A.Obzhirov and B. Baranov, $140 \mathrm{p}$.

15. Young-Gyun Kim, Sang-Mook Lee, Young Keun Jin, Boris Baranov, Anatoly Obzhirov, Alexander Salomatin, Hitoshi Shoji. Marine and Petroleum Geology, 45 (2013)

16. Yusupov V., Salomatin A., Obzhirov A. Gas-Geophysical complex to search underwater gas hydrate. (Patent. RU № 70377 U1, 2008. Bull. No 2) 